\title{
Role of Serum Cytokine Levels in Acute Respiratory Distress Syndrome Patients on Extracorporeal Membrane Oxygenation Support
}

\author{
Ena Gupta1, Kyle Carey², Lydia McDermott³, Nicholas Cavarocchi ${ }^{3}$ Hitoshi Hirose ${ }^{3}$, \\ Michael Baram $^{1 *}$ \\ ${ }^{1}$ Division of Pulmonary and Critical Care, Thomas Jefferson University, Philadelphia, PA, USA \\ ${ }^{2}$ Sidney Kimmel Medical College at Thomas Jefferson University, Philadelphia, PA, USA \\ ${ }^{3}$ Division of Cardiothoracic Surgery, Thomas Jefferson University, Philadelphia, PA, USA \\ Email: enagupta8@gmail.com, kyle.carey@jefferson.edu, Lydia.mcdermott@jefferson.edu, nicholas.cavarocchi@jefferson.edu, \\ hitoshi.hirose@jefferson.edu, *Michael.baram@jefferson.edu
}

How to cite this paper: Gupta, E., Carey, K., McDermott, L., Cavarocchi, N., Hirose, H. and Baram, M. (2020) Role of Serum Cytokine Levels in Acute Respiratory Distress Syndrome Patients on Extracorporeal Membrane Oxygenation Support. World Journal of Cardiovascular Surgery, 10, 1-10. https://doi.org/10.4236/wjcs.2020.101001

Received: December 16, 2019

Accepted: January 14, 2020

Published: January 17, 2020

Copyright $\odot 2020$ by author(s) and Scientific Research Publishing Inc. This work is licensed under the Creative Commons Attribution International License (CC BY 4.0).

http://creativecommons.org/licenses/by/4.0/

\begin{abstract}
Background: Even with the use of extracorporeal membrane oxygenation (ECMO) in acute respiratory distress syndrome (ARDS), mortality remains high. Also, prognostication of patients with ARDS and ECMO is difficult. Cytokines are thought to be markers of inflammation in both ARDS and in ECMO, however, understanding is limited. We aimed to study the association of three serum cytokine levels with mortality in these patients with ARDS on ECMO. Methods: We performed a retrospective chart review of ARDS patients on ECMO between 2011 and 2017. Patients with serum TNF- $\alpha$, IL-6 and IL-2 measured while on ECMO were included, with measurements recorded weekly up to a maximum of 4 measurements. A multivariable regression analysis was performed and generalizing estimating equations were used to analyze longitudinal trend of cytokines with mortality. Results: There were 47 patients with ARDS on ECMO, of which 31 (68.9\%) survived at 30 days and 2 were lost to follow up. Initial IL-2 levels were found to be significantly higher among those who were alive compared to those who died at 30 days $(2720 \pm 2432 \mathrm{pg} / \mathrm{ml}$ vs. $1293 \pm 693 \mathrm{pg} / \mathrm{ml}) ; \mathrm{p}=0.0460$. At any given time, an increase in IL-2 was associated with a decrease in odds of death at 30 days (adjusted odds ratio $0.98,95 \%$ confidence interval $0.97-0.99, \mathrm{p}=0.08$ ). There was no significant difference in average or initial levels of TNF- $\alpha$ and IL- 6 among those who were alive vs. those who died at 30 days. There was no association between either of these cytokine levels with death while on ECMO. Conclusions: Higher levels of cytokine IL-2 were associated with
\end{abstract}


lower 30-day mortality. Further studies are needed to elucidate the pathobiology of cytokines while on ECMO and their use in predicting outcomes.

\section{Keywords}

Serum Cytokines, ECMO, ARDS, Mortality

\section{Introduction}

Acute respiratory distress syndrome (ARDS) is an inflammatory process that is triggered by a variety of insults that result in disruption of the alveolar-capillary barrier. Although the triggers for ARDS can vary, the inflammatory pathway is better understood now, compared to when ARDS was first described by Petty et al. [1]. Cytokine pathways have been implicated in pathogenesis, however, there remains a poor understanding of the modulation of the host response to stresses. Depending on the degree of inflammation, this may result in different phenotypes of severity of diffuse pulmonary edema and life-threatening respiratory failure. Current estimates of mortality range from 35\% - 45\% depending on severity [2]. Unbridled inflammation results in multi-organ failure and death [3]. Current ARDS ventilatory strategies revolve around reducing inflammation caused by ventilators [4].

Lung protective ventilation strategy is essential to limit and mitigate inflammation [5]. ECMO allows for ultra-low tidal volume thereby protecting the lung from the deleterious shear and stress forces of the ventilator [6]. Although the timing and selection for ECMO use remain debated, since the $2009 \mathrm{H}_{1} \mathrm{~N}_{1}$ epidemic, ECMO has been used in moderate and severe ARDS [7]. Its utilization in ARDS has been growing [8]. Despite the protective nature of ECMO from lung stress, the initiation of ECMO also produces an inflammatory response similar to systemic inflammatory response syndrome (SIRS) [9]. This response is thought to be induced both by extrinsic factors like contact activation with the extracorporeal circuit and intrinsic factors like tissue damage and endothelial cell activation [10] [11]. It is unknown if this excessive systemic inflammatory reaction may have detrimental effects and cause organ damage and failure. Not only does the initiation of ECMO result in SIRS, but the decannulation results in a similar picture [12].

Cytokines are regarded as important mediators in the systemic inflammatory response to extracorporeal circuits. The effects of cytokines on mortality are not fully understood. Various pro-inflammatory and anti-inflammatory cytokines are released at the same time causing dysregulated inflammatory homeostasis. These can potentially serve as biomarkers for the inflammatory state and aid in prognosticating and management strategies. Current understanding of these cytokines and their role in pathophysiology is limited.

Among the proinflammatory cytokines, TNF- $\alpha$ is commonly produced by a variety of cells in response to inflammatory stimulus. Higher levels of TNF- $\alpha$ 
have been associated with non-survival in neonates undergoing ECMO [13]. Interleukin- 6 is a complicated cytokine, with both pro- and anti-inflammatory actions. In a study by Risnes et al., levels of IL- 6 were inversely related to survival among children and adults on ECMO [14]. This association was not seen in other cytokines studies including IL1- $\beta$, IL-8 or IL-10 [14]. IL-2 controls the function of regulatory $\mathrm{T}$ cells and has not been well studied on the ECMO population. Its major physiological function is to limit rather than enhance $\mathrm{T}$ cell responses [15]. Hence making it relevant in the interplay of pro and anti-inflammatory cytokines.

This study aims to quantify and determine the significance of the serum concentration of TNF- $\alpha$, IL- 6 , and IL- 2 with 30 -day mortality in patients with ARDS on ECMO.

\section{Methods}

A retrospective chart review of patients admitted to a tertiary medical center with a well-developed ECMO program between 2011 and 2017 was performed. Patients who were initiated on ECMO for ARDS and had serum cytokine levels measured were included. ECMO initiated for cardiac failure or patients who did not have sufficient cytokine measurements were excluded from this study. Baseline characteristics, laboratory values, admission diagnosis, indication for ECMO, and ventilatory parameters were collected after ECMO initiation. This study was approved by the institutional review board of Thomas Jefferson University Hospital.

The primary end-point of this study was survival on ECMO and vital status at 30 days after discharge. ECMO death was defined as death within 24 hours of ECMO discontinuation. Thirty-day survival was defined by 30 -day survival after ECMO discontinuation.

Serum levels of TNF- $\alpha$, IL-2, and IL-6 levels were recorded weekly in these study patients with a maximum of four measurements. If more than one value was collected for any particular week, the average of the two values was calculated and used as the value for that week. Due to a physiological wide range of concentrations of inflammatory markers, laboratories often use prozone analytic algorithms to measure and report inflammatory data.

Categorical variables were reported as numbers (percentages) and continuous variables were reported as means (standard deviation). Single variable comparison performed by student t-test for continuous variables and chi-square for categorical variables. Average level of all three cytokines was analyzed among those who were alive at 30 days vs. those who died at 30 days. The first collected cytokine level was also compared between the two groups. Similar analysis was performed for mortality on ECMO.

Additional multivariable regression analysis was performed to evaluate the effect of initial and average cytokine levels with 30-day mortality. After adjusting known and plausible causes of mortality in the regression analysis, logistic regression was performed using generalizing estimating equations using logit link 
and binomial family to analyze the association of trend of cytokine level in serum on 30-day mortality accounting for the longitudinal data and multiple values for each patient. Odds ratio (OR) was expressed with $95 \%$ confidence intervals $(\mathrm{CI})$.

\section{Results}

There were 47 patients eligible for the study. The average age was 46 years (range 23 - 73 years $)$ and $62 \%(n=29)$ were males. All of the patients had diagnosis of ARDS and the majority $(n=35,75 \%)$ of them were on veno-venous (VV) ECMO. Baseline characteristics of the cohort are represented in Table 1.

Forty-seven patients treated with ECMO for their ARDS between 2011 and 2017 were identified that had any cytokine levels drawn. Due to the urgent nature of ECMO cannulation, there was some clinician variability in the timing and consistency of laboratory draws. There are 81 observations for IL-2 among 43 individuals. The average IL-2 value was $2396 \mathrm{pg} / \mathrm{ml}$ with a range of 252 $12,420 \mathrm{pg} / \mathrm{ml}$. There were 81 observations for IL-6 among 44 individuals. Average IL-6 was $917 \mathrm{pg} / \mathrm{ml}$ with a range of $0-45,440 \mathrm{pg} / \mathrm{ml}$ among 42 patients. There were 80 observations for TNF- $\alpha$ among 41 individuals. Average TNF- $\alpha$ was $12 \mathrm{pg} / \mathrm{ml}$ with a range of $1-279 \mathrm{pg} / \mathrm{ml}$.

Table 2 compares the average and initial levels for IL-2, IL- 6 and TNF- $\alpha$ among patients who were alive at 30 days vs. those who died at 30 days. Average IL-2 was higher among those who survived as compared to those who died (2521 $\pm 1641 \mathrm{pg} / \mathrm{ml}$ vs. $1265 \pm 630 \mathrm{pg} / \mathrm{ml} ; \mathrm{p}=0.011)$. Similarly, initial IL-2 was higher among those who survived as compared to those who died $(2720 \pm 2432 \mathrm{pg} / \mathrm{ml}$ vs. $1293 \pm 693 \mathrm{pg} / \mathrm{ml} ; \mathrm{p}=0.046)$. There was no significant difference found in the average or initial concentration of TNF- $\alpha$ and IL- 6 between patients that survived to 30-days and those that did not. Table 3 shows no difference in the average or initial levels of IL-2, IL-6 and TNF- $\alpha$ with survival on ECMO.

In multivariable regression analysis, higher initial IL-2 was associated with decrease in OR of 30-day mortality (adjusted OR 0.998, 95\% CI $0.997-0.999, \mathrm{p}$ $=0.021$ ) after adjusting for age, sex, BMI, race, VA (veno-arterial) vs. VV (veno-venous) ECMO, sepsis and days on ECMO. No association was seen with initial TNF- $\alpha(\mathrm{p}=0.869)$ and IL-6 $(\mathrm{p}=0.417)$ and 30-day mortality. Additionally, using generalized estimating equations, an increase of IL-2 at any time during ECMO was associated with a decrease in odds of 30-day mortality after adjusting for age, sex and race (OR 0.98, 95\% CI $0.97-0.99, \mathrm{p}=0.08$ ). No association was seen with the trend of TNF- $\alpha(\mathrm{p}=0.911)$ or IL-6 $(\mathrm{p}=0.426)$ with 30-day mortality.

The exploratory analysis compared those categorized IL-2 as low IL-2 or high IL-2 based on median value of the group. Table 4 shows the distribution of etiology of ARDS in patients with IL-2 below the median value of $1724 \mathrm{pg} / \mathrm{ml}$ vs higher than the median value of $1724 \mathrm{pg} / \mathrm{ml}$. The high IL-2 group had higher percentage of infectious etiologies of ARDS including viral, bacterial and fungal pneumonias. Whereas the low IL-2 group had higher percentage of non-infectious 
etiologies including interstitial pneumonitis, myocardial infarction, aspiration pneumonias and other etiologies including contusion, drug overdose, alveolar hemorrhage.

Table 1. Baseline characteristics of the study patients with ARDS on ECMO. Data are expressed number (percentage), or mean \pm standard deviation.

\begin{tabular}{cc}
\hline Number of patients & 47 \\
Age, years & $46 \pm 12$ \\
Male gender & $29 \pm 62$ \\
VV ECMO & $35(75 \%)$ \\
Body mass index kg/m ${ }^{2}$ & $34 \pm 10$ \\
Sepsis & $2(4.3 \%)$ \\
Transfer from outside hospital & $27(58 \%)$ \\
Chronic Steroid use & $3(6.4 \%)$ \\
Chronic lung disease & $11(24 \%)$ \\
Coronary artery disease & $4(8.5 \%)$ \\
Diabetes & $13(28 \%)$ \\
\hline
\end{tabular}

VV ECMO: Veno-venous extracorporeal membrane oxygenation.

Table 2. Comparison of average and initial levels of TNF- $\alpha$, IL-6 and IL-2 among those who were alive at 30 days vs. those who died at 30 days. Data are expressed mean \pm standard deviation.

\begin{tabular}{ccccc}
\hline & $\begin{array}{c}\text { Alive at 30 days } \\
\mathbf{n}=\mathbf{3 3}(\mathbf{7 0 . 2 \%})\end{array}$ & $\begin{array}{c}\text { Died at 30 days } \\
\mathbf{n = 1 4}(\mathbf{2 9 . 8 \% )}\end{array}$ & $\begin{array}{c}\text { Total } \\
\text { population }\end{array}$ & p-value \\
\hline Number of patients & $31(68.9)$ & $14(31.1)$ & 45 & \\
Average TNF- $\alpha(\mathrm{pg} / \mathrm{ml})$ & $13 \pm 32$ & $14 \pm 24$ & $13 \pm 29$ & 0.932 \\
Initial TNF- $\alpha(\mathrm{pg} / \mathrm{ml})$ & $16 \pm 51$ & $12 \pm 24$ & $14 \pm 44$ & 0.854 \\
Average IL-6 (pg/ml) & $832 \pm 3294$ & $545 \pm 1609$ & $716 \pm 2797$ & 0.768 \\
Initial IL-6 (pg/ml) & $1940 \pm 8424$ & $568 \pm 1613$ & $1458 \pm 6885$ & 0.566 \\
Average IL-2 (pg/ml) & $2521 \pm 1641$ & $1265 \pm 630$ & $2100 \pm 1479$ & 0.011 \\
Initial IL-2 $(\mathrm{pg} / \mathrm{ml})$ & $2720 \pm 2432$ & $1293 \pm 693$ & $2266 \pm 2094$ & 0.046 \\
\hline
\end{tabular}

Table 3. Comparison of average and initial levels of TNF- $\alpha$, IL-6 and IL-2 among those who survived at ECMO vs. those who died on ECMO. Data are expressed mean \pm standard deviation.

\begin{tabular}{ccccc}
\hline & $\begin{array}{c}\text { Survived ECMO } \\
\mathbf{n}=\mathbf{3 8}(\mathbf{8 0 . 8 \%})\end{array}$ & $\begin{array}{c}\text { Died on ECMO } \\
\mathbf{n = 9 ( 1 9 . 1 \% )}\end{array}$ & $\begin{array}{c}\text { Total } \\
\text { population }\end{array}$ & p-value \\
\hline Number of patients & $38(80.85)$ & $9(19.15)$ & 47 & \\
Average TNF- $\alpha(\mathrm{pg} / \mathrm{ml})$ & $14 \pm 38$ & $5.9 \pm 3.7$ & $12 \pm 34$ & 0.419 \\
Initial TNF- $\alpha(\mathrm{pg} / \mathrm{ml})$ & $16 \pm 48.3$ & $5.6 \pm 5$ & $14.3 \pm 44$ & 0.574 \\
Average IL-6 $(\mathrm{pg} / \mathrm{ml})$ & $1017 \pm 5677$ & $504 \pm 1451$ & $917 \pm 5127$ & 0.722 \\
Initial IL-6 $(\mathrm{pg} / \mathrm{ml})$ & $1589 \pm 7570$ & $871 \pm 2044$ & $1458 \pm 6885$ & 0.793 \\
Average IL-2 $(\mathrm{pg} / \mathrm{ml})$ & $2347 \pm 1874$ & $2582 \pm 3028$ & $2396 \pm 2147$ & 0.691 \\
Initial IL-2 $(\mathrm{pg} / \mathrm{ml})$ & $2156 \pm 1475$ & $2679 \pm 3716$ & $2266 \pm 2094$ & 0.512 \\
\hline
\end{tabular}


Table 4. Table comparing etiology of ARDS and ECMO in those with low IL-2 vs. those with high IL-2. Data are expressed number (percentage).

\begin{tabular}{ccc}
\hline & Low IL-2 $(<1724 \mathrm{pg} / \mathrm{ml})$ & High $1 \mathrm{~L}-2(\geq 1724 \mathrm{pg} / \mathrm{ml})$ \\
\hline Infectious etiology & $\mathbf{9 ( 4 1 \% )}$ & $\mathbf{1 4}(67 \%)$ \\
Bacterial pneumonia & $1(4.5 \%)$ & $5(23.8)$ \\
Viral pneumonia & $7(32 \%)$ & $8(38.1)$ \\
Fungal pneumonia & $1(4.6 \%)$ & $1(4.8)$ \\
Non-infectious etiology & $\mathbf{1 3 ( 5 9 \% )}$ & $\mathbf{7 ( 3 3 \% )}$ \\
Interstitial pneumonitis & $2(9.1 \%)$ & $0(0)$ \\
Myocardial infarction & $1(4.5 \%)$ & $1(4.8 \%)$ \\
Aspiration pneumonia & $5(23 \%)$ & $4(19 \%)$ \\
Pancreatitis & $1(4.5 \%)$ & $1(4.8 \%)$ \\
Other & $4(19 \%)$ & $1(4.8 \%)$ \\
\hline
\end{tabular}

\section{Discussion}

The inflammatory response to ECMO is complex and multi-faceted and the components of the response are not well understood. It is unclear why there is a varying degree of response in various individuals or if this excess inflammation is all deleterious. Also, there is a need for markers to predict and identify worsening inflammatory conditions during ECMO in order to improve outcomes by implementing changes in treatment.

This study showed that higher initial and higher overall average serum concentrations of IL-2 were associated with lower 30-day mortality. An increase in serum IL-2 concentration at any time was associated with a decrease in odds of death at 30 days. However, no relationship was seen between serum concentrations of TNF- $\alpha$ or IL- 6 on 30-day mortality.

IL-2, also named T-cell growth factor, is generally considered to promote $\mathrm{T}$-cell proliferation and enhance effector $\mathrm{T}$-cell function It has been shown to also play a key role in promoting the development, homeostasis and function of regulatory T cells (Tregs) though IL-2/STAT5 signals [16]. Tregs indirectly limit immune inflammation-inflicted tissue damage by employing multiple mechanisms and creating the appropriate immune environment for successful tissue repair. Research has confirmed that the neutrophil clearance rate can be accelerated by Tregs [17] [18]. Clinical trials have shown that using low-dose IL-2 can control autoimmune inflammation safely and effectively by expanding Treg cells and modulating immune pathologies in various diseases like graft vs host disease, type I diabetes, hepatitis C induced vasculitis [19] [20] [21]. It is therefore possible that elevation in IL-2 while on ECMO helps to control the dysregulated immune response due to ECMO and hence the noted improvement in mortality in our study.

It is unclear as to what causes this variation in IL-2 levels in our study population. There was higher IL-2 in infectious causes as opposed to non-infectious 
causes in our study. It is possible that the elevated levels of IL-2 represents a proinflammatory endotype of ARDS and hence portends a better prognosis. Calfee et al. conducted a study that supports the possibility of two phenotypes of ARDS and found a difference in serum concentration of inflammatory cytokines between the identified groups [22]. Of the two phenotypes identified in this study, the group with higher serum inflammatory cytokine concentrations was associated with sepsis-related ARDS and the group with lower serum inflammatory cytokines concentrations was associated with trauma-related ARDS. Hence future studies on ECMO and ARDS might benefit from identification of these endotypes.

TNF- $\alpha$ is produced in response to inflammatory stimuli [23]. TNF- $\alpha$ supports the inflammatory process through inflammatory cell activation, stimulating the production of other proinflammatory cytokines, and generation of reactive oxygen species [24]. While IL-6 is often described as having both pro- and anti-inflammatory characteristics [25], there is evidence to support the idea that IL-6 and TNF- $\alpha$ play a similar role in the development of a systemic inflammatory response [26]. However, it is unclear if this inflammatory response is a marker of disease severity or responsible for pathogenesis of disease. Also, it is unclear if targeting this response would be beneficial in patients on ECMO. For example, in sepsis, TNF- $\alpha$ and IL- $1 \beta$ have been shown to play a significant role in development and progression of inflammation, however, clinical trials directed at neutralizing TNF- $\alpha$ and IL- $1 \beta$ have not shown a significant improvement in outcome or the onset of lung injury [27] [28]. Our study also did not show any association of TNF- $\alpha$ or IL-6 with 30-day mortality in patients with ARDS and ECMO. It is also possible that the measurement of IL- 6 and TNF- $\alpha$ in the serum is more challenging as evidenced by the reporting of prozone effect in many samples in our study.

This study has several limitations. First, the retrospective design lends itself to some inherent biases and misclassification. Second, the weekly measurement of cytokine levels was not correlated with worsening disease or interventions that can potentially alter cytokine levels in individual patients. Third, there is lack of standardization in measurement of these assays. The send out laboratory underwent changes in their process of measurement during the study period. Due to normal physiologic wide distribution of the data, reported data may be affected by the prozone effect used in the laboratory for standardization of the report. Fourth, due to logistical reasons, not all patients with ARDS and ECMO had cytokine levels measured during the study period. Lastly, we did not measure cytokine levels before the initiation of ECMO, so it is impossible to know if they fell or rose in an individual patient.

Despite these shortcomings, this study helps in advancing the understanding of a few of the cytokines involved in the process and paves the way for both basic science and clinical studies. This is one of the first studies looking at the association of IL-2 with 30-day mortality in those with ARDS on ECMO. Even though it is unlikely that any particular cytokine will be a master cytokine to explain all 
the underlying mechanisms of the disease process, it is worthwhile to study these mediators for potential newer treatment strategies to help improve outcomes. More studies are needed to study the interplay of cytokines and their role in the prognostication in ECMO and ARDS.

\section{Conclusion}

A higher average or initial IL-2 concentration and an increase in IL-2 concentration were associated with decrease in 30-day mortality in patients with ARDS in ECMO. This finding is consistent with previously shown protective mechanisms of IL-2 in other hyperimmune conditions. However, additional studies are needed to evaluate the role and therapeutic potential of IL-2 in ARDS patients on ECMO. No significant association was seen between serum levels of TNF- $a$ or IL-6 with 30-day mortality. The complexity of these assays, long turn-over time, and lack of standardization and understanding are some of the barriers for future studies utilizing cytokines in the ECMO population.

\section{Author Contributions}

All authors listed have contributed sufficiently to the project to be included as authors, and all those who are qualified to be authors are listed in the author by-line.

\section{Conflicts of Interest}

The authors declare no conflicts of interest regarding the publication of this paper.

\section{References}

[1] Petty, T.L. (2001) In the Cards Was ARDS: How We Discovered the Acute Respiratory Distress Syndrome. American Journal of Respiratory and Critical Care Medicine, 163, 602-603. https://doi.org/10.1164/ajrccm.163.3.16331

[2] Bellani, G., Laffey, J.G., Pham, T., Fan, E., Brochard, L., Esteban, A., et al. (2016) Epidemiology, Patterns of Care, and Mortality for Patients with Acute Respiratory Distress Syndrome in Intensive Care Units in 50 Countries. JAMA, 315, 788-800. https://doi.org/10.1001/jama.2016.0291

[3] Dolinay, T., Kim, Y.S., Howrylak, J., Hunninghake, G.M., An, C.H., Fredenburgh, L., et al. (2012) Inflammasome-Regulated Cytokines Are Critical Mediators of Acute Lung Injury. American Journal of Respiratory and Critical Care Medicine, 185, 1225-1234. https://doi.org/10.1164/rccm.201201-0003OC

[4] Papazian, L., Aubron, C., Brochard, L., Chiche, J.D., Combes, A., Dreyfuss, D., et al. (2019) Formal Guidelines: Management of Acute Respiratory Distress Syndrome. Annals of Intensive Care, 9, Article No. 69. https://doi.org/10.1186/s13613-019-0540-9

[5] Awsare, B., Herman, J. and Baram, M. (2017) Management Strategies for Severe Respiratory Failure: As Extracorporeal Membrane Oxygenation Is Being Considered. Critical Care Clinics, 33, 795-811. https://doi.org/10.1016/j.ccc.2017.06.003

[6] Protti, A., Andreis, D.T., Monti, M., Santini, A., Sparacino, C.C., Langer, T., et al. (2013) Lung Stress and Strain during Mechanical Ventilation: Any Difference be- 
tween Statics and Dynamics? Critical Care Medicine, 41, 1046-1055. https://doi.org/10.1097/CCM.0b013e31827417a6

[7] Brodie, D. and Bacchetta, M. (2011) Extracorporeal Membrane Oxygenation for ARDS in Adults. New England Journal of Medicine, 365, 1905-1914. https://doi.org/10.1056/NEJMct1103720

[8] Clark, J.B., Wang, S., Palanzo, D.A., Wise, R., Baer, L.D., Brehm, C., et al. (2015) Current Techniques and Outcomes in Extracorporeal Life Support. Artificial Organs, 39, 926-930. https://doi.org/10.1111/aor.12527

[9] Davies, M.G. and Hagen, P.O. (1997) Systemic Inflammatory Response Syndrome. The British Journal of Surgery, 84, 920-935. https://doi.org/10.1002/bjs.1800840707

[10] Tomic, V., Russwurm, S., Moller, E., Claus, R.A., Blaess, M., Brunkhorst, F., et al. (2005) Transcriptomic and Proteomic Patterns of Systemic Inflammation in On-Pump and Off-Pump Coronary Artery Bypass Grafting. Circulation, 112, 2912-2920. https://doi.org/10.1161/CIRCULATIONAHA.104.531152

[11] Chew, M.S., Brandslund, I., Brix-Christensen, V., Ravn, H.B., Hjortdal, V.E., Pedersen, J., et al. (2001) Tissue Injury and the Inflammatory Response to Pediatric Cardiac Surgery with Cardiopulmonary Bypass: A Descriptive Study. Anesthesiology, 94, 745-753. https://doi.org/10.1097/00000542-200105000-00010

[12] Thangappan, K., Cavarocchi, N.C., Baram, M., Thoma, B. and Hirose, H. (2016) Systemic Inflammatory Response Syndrome (SIRS) after Extracorporeal Membrane Oxygenation (ECMO): Incidence, Risks and Survivals. Heart \& Lung, 45, 449-453. https://doi.org/10.1016/j.hrtlng.2016.06.004

[13] Plotz, F.B., van Oeveren, W., Bartlett, R.H. and Wildevuur, C.R. (1993) Blood Activation during Neonatal Extracorporeal Life Support. The Journal of Thoracic and Cardiovascular Surgery, 105, 823-832. https://doi.org/10.1016/S0022-5223(19)34156-X

[14] Risnes, I., Wagner, K., Ueland, T., Mollnes, T., Aukrust, P. and Svennevig, J. (2008) Interleukin-6 May Predict Survival in Extracorporeal Membrane Oxygenation Treatment. Perfusion, 23, 173-178. https://doi.org/10.1177/0267659108097882

[15] Nelson, B.H. (2004) IL-2, Regulatory T Cells, and Tolerance. Journal of Immunolo$g y$, 172, 3983-3988. https://doi.org/10.4049/jimmunol.172.7.3983

[16] Ye, C., Brand, D. and Zheng, S.G. (2018) Targeting IL-2: An Unexpected Effect in Treating Immunological Diseases. Signal Transduction and Targeted Therapy, 3, Article No. 2. https://doi.org/10.1038/s41392-017-0002-5

[17] D’Alessio, F.R., Tsushima, K., Aggarwal, N.R., West, E.E., Willett, M.H., Britos, M.F., et al. (2009) $\mathrm{CD}^{+} \mathrm{CD} 25^{+}$Foxp $3^{+}$Tregs Resolve Experimental Lung Injury in Mice and Are Present in Humans with Acute Lung Injury. Journal of Clinical Investigation, 119, 2898-2913. https://doi.org/10.1172/JCI36498

[18] Matthay, M.A., Ware, L.B. and Zimmerman, G.A. (2012) The Acute Respiratory Distress Syndrome. Journal of Clinical Investigation, 122, 2731-2740. https://doi.org/10.1172/JCI60331

[19] He, J., Zhang, X., Wei, Y., Sun, X., Chen, Y., Deng, J., et al. (2016) Low-Dose Interleukin-2 Treatment Selectively Modulates CD4 ${ }^{+} \mathrm{T}$ Cell Subsets in Patients with Systemic Lupus Erythematosus. Nature Medicine, 22, 991-993. https://doi.org/10.1038/nm.4148

[20] Koreth, J., Matsuoka, K., Kim, H.T., McDonough, S.M., Bindra, B., Alyea, E.P., et al. (2011) Interleukin-2 and Regulatory T Cells in Graft-versus-Host Disease. The New England Journal of Medicine, 365, 2055-2066.

https://doi.org/10.1056/NEJMoa1108188 
[21] Saadoun, D., Rosenzwajg, M., Joly, F., Six, A., Carrat, F., Thibault, V., et al. (2011) Regulatory T-Cell Responses to Low-Dose Interleukin-2 in HCV-Induced Vasculitis. The New England Journal of Medicine, 365, 2067-2077. https://doi.org/10.1056/NEJMoa1105143

[22] Calfee, C.S., Delucchi, K., Parsons, P.E., Thompson, B.T., Ware, L.B. and Matthay, M.A. (2014) Subphenotypes in Acute Respiratory Distress Syndrome: Latent Class Analysis of Data from Two Randomised Controlled Trials. The Lancet Respiratory Medicine, 2, 611-620. https://doi.org/10.1016/S2213-2600(14)70097-9

[23] Millar, J.E., Fanning, J.P., McDonald, C.I., McAuley, D.F. and Fraser, J.F. (2016) The Inflammatory Response to Extracorporeal Membrane Oxygenation (ECMO): A Review of the Pathophysiology. Critical Care (London, England), 20, 387. https://doi.org/10.1186/s13054-016-1570-4

[24] Mukhopadhyay, S., Hoidal, J.R. and Mukherjee, T.K. (2006) Role of TNF $\alpha$ in Pulmonary Pathophysiology. Respiratory Research, 7, Article No. 125. https://doi.org/10.1186/1465-9921-7-125

[25] Xing, Z., Gauldie, J., Cox, G., Baumann, H., Jordana, M., Lei, X.F., et al. (1998) IL-6 Is an Antiinflammatory Cytokine Required for Controlling Local or Systemic Acute Inflammatory Responses. Journal of Clinical Investigation, 101, 311-320. https://doi.org/10.1172/JCI1368

[26] Fattori, E., Cappelletti, M., Costa, P., Sellitto, C., Cantoni, L., Carelli, M., et al. (1994) Defective Inflammatory Response in Interleukin 6-Deficient Mice. Journal of Experimental Medicine, 180, 1243-1250. https://doi.org/10.1084/jem.180.4.1243

[27] Goodman, R.B., Strieter, R.M., Martin, D.P., Steinberg, K.P., Milberg, J.A., Maunder, R.J., et al. (1996) Inflammatory Cytokines in Patients with Persistence of the Acute Respiratory Distress Syndrome. American Journal of Respiratory and Critical Care Medicine, 154, 602-611. https://doi.org/10.1164/ajrccm.154.3.8810593

[28] Opal, S.M. and Cross, A.S. (1999) Clinical Trials for Severe Sepsis. Past Failures, and Future Hopes. Infectious Disease Clinics of North America, 13, 285-297. https://doi.org/10.1016/S0891-5520(05)70075-1 